\title{
CORRECTION
}

\section{Validation of the Ottawa \\ Subarachnoid Hemorrhage \\ Rule in patients with acute \\ headache}

CMAJ has been made aware of an error that occurred in the Nov. 13, 2017, issue. ${ }^{1}$

The following statement should have been included in the funding statement of this article:

This study was funded by the Canadian Institutes of Health Research (CIHR) (Grant nos. 67107 and 148382).

- Cite as: CMAJ 2018 February 12;190:

E173. doi: $10.1503 / \mathrm{cmaj} .180092$

\section{Reference}

1. Perry JJ, Sivilotti MLA, Sutherland J, et al. Validation of the Ottawa Subarachnoid Hemorrhage Rule in patients with acute headache. CMAJ 2017;189:E1379-85. 